\title{
Home Culture Attachment and Comprehending L2 Written Texts: A Study on EFL learners in Iran
}

\author{
Mahshid Hejazi \\ PhD Candidate, Ferdowsi University of Mashhad, International Campus, Iran \\ Email:ma.hejazi@stu.um.ac.ir \\ Behzad Ghonsooly \\ Corresponding Author, Professor, Ferdowsi University of Mashhad, Iran \\ Postal Address: Department of English Language and Literature, \\ Faculty of Letters and Humanities, Ferdowsi University of Mashhad. Mashhad- Iran \\ Email: ghonsooly@um.ac.ir \\ Reza Pishghadam \\ Professor, Ferdowsi University of Mashhad, Iran \\ Email: pishghadam@um.ac.ir

\section{Hesamoddin Shahriari Ahmadi} \\ Assistant Professor, Ferdowsi University of Mashhad, Iran \\ Email: h.Shahriari@um.ac.ir
}

Doi:10.5901/mjss.2015.v6n4s3p383

\begin{abstract}
Most research on second language and culture concentrates on learning the target culture in order to better understand the second language. This survey study looks at culture from a different perspective i.e., from the learners' own culture point of view. It focuses on the relationship that exists between attachment to one's home culture and comprehending written texts in a foreign language. This study clarifies some of the hindering factors that are involved in miscomprehending or not comprehending the $L 2$ written passages which can be noteworthy both for L2 teachers and L2 learners. In this study 228 homogeneous L2 learners participated. They took TOEFL reading tests and filled out a Home Culture Attachment questionnaire. This study found that among the underlying factors of the scale, Religious and Nationality attachments had negative relationships with the reading score of the learners. It can be inferred from the findings that being biased towards some beliefs may limit the flexibility of the mind in the process of comprehending L2 passages.
\end{abstract}

Keywords: Culture, Home Culture, Home Culture Attachment, Reading comprehension

\section{Introduction}

A dramatic change in the real world and in language pedagogy has taken place in recent decades. Due to the increasing pace of globalization, electronic communication, popular media, the internet, and social networks, our lives are affected to varying degrees and their effects are more profound on young people and language students (Hinkel, 2012).Since these advancements break down barriers and borders among nations, the aim of foreign language education has now been expanded to include fostering and elevating the understanding and the acceptance of other cultures (Sellami, 2000).

According to Kramsch 1998, culture both liberates and limits people. It frees them from the randomness of nature and limits them by imposing on them the structures and principles based on which selections has to be done. As Matsumoto and Juang (2004) state, culture like a lens rotates and directs us to see the world from our own view point (cited in Keith, 2011, p.22).

On the one hand, since a language cannot be learned without considering the cultural context in which it is used, second language learners inescapably become the learners of the second culture (Hinkel, 1999), on the other hand, according to Byram and Morgan (1994) "learners cannot simply shake off their own culture and step into another.... their 
culture is part of themselves and created them as social beings" (p.43).

Regarding the mentioned considerations, this study seeks to answer the following questions:

Q1: Is there a relationship between the EFL learners' home culture attachment and their reading achievement?

Q2: Is there a relationship between the EFL learners' home culture attachment subscales and the learners' reading comprehension?

Q3: Which subscales are predictors of reading comprehension?

\section{Literature Review}

The reviewed literature in this study primarily focuses on the status of culture in first and second languages then on the significant role that cultural schema plays on comprehending written texts and ultimately on different views language learners choose to take toward their home culture while encountering another language and culture.

\subsection{Culture and Language}

In browsing the literature on a general level Lado (1957) refers to culture as "the ways of people" including both material and non-material manifestations. Culture is more specifically outlined in four different meanings: (1) The aesthetic sense that includes cinema, literature, music, and media. (2) The sociological sense which refers to organization and nature of family, interpersonal relations, customs, and material conditions (3) The semantic sense that is the whole conceptualization system which conditions perceptions and thought processes. (4) The pragmatic or sociolinguistic sense that refers to the background knowledge, social and paralinguistic skills, and language code which are necessary for successful communication (Adaskou, Britten, \& Fashi, 1990, pp.3-4). Culture like language is dynamic and is constantly changing (Robinson, 1988).

Edward Sapir (1884-1939) and his pupil, Benjamin Whorf, stated that a language and the culture of its speakers cannot be analyzed in isolation. According to Sapir, language can be seen as a way to describe and represent human experience and an understanding of the world, and typically, members of a language community share a common system of beliefs and assumptions in regard to how the world is constructed. They also determined that in different languages, linguistic systems, discourse, and word meanings demonstrate different ways of looking at the world and constructing its realities (Hinkel, 1999).

Language and culture are tightly related with each other. Language carries culture and all its components like beliefs, customs, objects, arts, and techniques. They all can be described, analyzed and evaluated by language. Language also reflects culture, meaning that it is influenced and shaped by culture. Language and culture interact. Understanding one requires an understanding of the other. The emergence of both of them is simultaneous in human history (Kun, 2013). According to Shahsavandi, Ghonsooly, and Kamyabi, (2010), scholars consider culture and language as integrated, and they cannot be viewed as separate and as two distinct entities.

The importance of culture in foreign language education has considerably increased since the early 1990s (Buttjes, 1990; Shotton, 1991; Taylor, 1991), and culture is acknowledged as a key element in education (Clouet, 2006).

Language is understood with reference to its social meaning and is not a neutral medium of communication (Peirce, 1995). Since there are different patterns of social structures and ordering in everyday communicative events, L2 learners' concepts cannot equally be interpreted through a second language (Lin, 2009). Mitchell and Myles (1998) believe language learning is an "essentially social" process and the learner is a social being whose identity is continuously reconstructed through engagement with the $L 2$. Second or foreign language learning therefore is not just a matter of code switching between two languages (Lin, 2009). Many aspects of L2 learning may be affected by the interpretive principles and paradigms in learners' natal culture (Hinkel, 1999). An individual's home cultural ideology derives from the society in which he or she lives and the reality he or she constructs (Lin, 2009). According to Jimenez (2000) the development of students' identity of their home and host cultures may foster interpersonal relationship. With the self-identity the learners receive from their home culture, they can confidently grasp pragmatic implications of the target language and perhaps make more progress in communicating through the target language (Lin, 2009).

When language learners internalize a new language and its new culture, they do not work in a vacuum. In fact, their beliefs, values, and assumptions shape their understanding of themselves and their understanding of others. They are embedded in the cultural context of their home society and this immersion lets them use this knowledge to interpret the meaning of linguistic concepts of the target language. Moreover, learning about another culture prompts students to reflect on their own culture. Language learners' local culture is their starting point and what they learn in this process goes back to their own culture (Kourova \& Modianos, 2013). Hence, the learner will always be some kind of mediator 
between the target culture and his/her own culture, thus having to interpret meaning all the time instead of acquiring fixed stereotypical notions (Clouet, 2006).

\subsection{L2 Reading and Cultural Schema}

Anderson (1999) defines reading as: "an active, fluent process that involves the reader and the reading material in building meaning. Meaning does not reside on the printed page.... Synergy occurs in reading, which combines the words on the printed page with the reader's background knowledge and experiences" (p.1).

Schema theory is based on the notion that "every act of comprehension involves one's knowledge of the world as well" (Anderson 1999, p.1) and as Widdowson (1983) states schema contains data structures of general ideas stored in memory. It is of two main categories: formal and content schema (Carrell, 1983,1987; Bernhardt, 1991). Formal schema is the knowledge of the language, and content schema refers to the background knowledge of the reader about the subject matter.

Readers combine linguistic and background knowledge to decode the written text (Dehghan \& Sadighi 2011). Anderson, Sapiro and Montague (1977), suggest that the cultural background of a reader affects her ability to understand a text. Cultural schema is an extension of content schema (Ketchum, 2006) and is developed ".... in the context of our basic experience" (Yule, 1996, p.87). Peirce (1868), states that "no cognition not determined by a previous cognition then can be known" in other words, we must use our inner, pre-existing cognition to make sense of the outer world, to detect and expand meaning. Tseng (1994) affirms that inner text is formed through our multiple experiences with the world. Meaning is generated as a result of transactions between our conception of the world and our confrontation with that world.

Many language practitioners have stated that cultural familiarity is significantly effective in reader's comprehension of reading texts (Steffensen, Joag-Dev, \& Anderson,1979; Carrell, 1987, \& Barnet, 1989). This can also be applied to foreign language reading in the sense that familiarity with foreign culture, helps understanding foreign written texts (Alptekin,2006; Steffensen et al., 1979). Besides familiarity with foreign culture it is important to be aware of one's own culture (Kramsch, 1993).

\subsection{Attaching to home culture or binding to it?}

At the time of second language learning, learners cannot completely separate themselves from their natal cultural context in order to interpret the meaning of linguistic information of the target language (Hinkel, 1999; Peirce, 1995; Tseng, 2002). Home culture symbolizes personal allegiance to their cultural heritage and has been deeply-seated in their minds. The sense of safety and security that comes from the learners' home culture identity ensures learners' confidence in using the target language (Lin, 2009).

Learning home culture knowledge and developing self-culture awareness serve as the basis for comparing and contrasting the two cultures which is an essential supplement to foreign language learners' target language learning and that leads to the development of their competence with target culture. Target language and culture learning also help language learners reflect and better understand their home culture, and learn about their own identity (Kun, 2013; Kramsch, 1993). In the same vein, Clouet (2005) asserts that the process of comparison and contrast will entail to appraisal of the target culture and greater understanding of learners' natal culture.

The interrelationship between home culture awareness and second language performance is not always sound. The incompatibility in behavior, attitudes, and values between ethnic and the mainstream cultures may cause psychological stress (Berry, Kin, Minde, \& Mon,1987; de Domanico, Crawford \& DeWolfe, 1994) in a similar vein the result of a study performed by Zhang, Morris, Cheng \& Yap in 2013 on immigrants indicated that heritage culture cues disrupt immigrants' second language processing through triggering first language interference.

Genc and Bada (2005) believe that some people are culture bound and espouse ethnocentric views; they reject and ignore the new culture and this leads to major problems when they face a different culture. They begin talking about the superiority of their culture as if it is possible to make a hierarchy of cultures. This is because they are unable to understand and accept people who have different points of view. Therefore, ethnocentricity limits the self so that when they begin to study another language, their restrictedness in their own culture prevents them from seeing the world through different ways of looking. Bada (2000) reminds that awareness of cultural values and societal characteristics does not necessarily invite the learner to accord with such values, after all they are there to "refine the self so that it can take a more universal and less egoistic form" (p.100).

Learning a language does not involve a change of one's cultural identity. Different cultures have different norms of 
behavior, but there is no inferiority or superiority in any of these norms. Critical cultural awareness involves both high sensitivity to cultural diversity and the ability to make an unbiased evaluation of both one's own and other cultural groups. Self-awareness and reflection on one's home culture can help learners get rid of ethnocentrism and develop an open and tolerant value system (Kun, 2013).

\section{Methodology}

\subsection{Participants}

This study was conducted on 228 EFL students: 72 males, 150 females / 6 missing. They were aged between 15- 56 . 145 of them were married, 76 were single / 7 missing. The participants held degrees ranging from first grade of high school to PhD: 8 high school degrees, 11 high school Diplomas, 3 Associates, 113 Bachelors, 73 Masters, 10 PhDs / 10 missing. They were majoring or have majored in different fields: 125 Humanities, 37 Engineering, 16 Medicine, 7 Agriculture, 33 Science / 10 missing. The learners were either studying EFL in language institutes or as their major discipline at universities. Their reading proficiency levels were upper intermediate and advanced. Their mother tongue was Farsi; they were all Iranian and Muslim. They were mostly residents of Mashhad which is a city in Northeast of Iran. Mashhad is a city of great religious significance and is a place for pilgrimage. It is most famous and revered for housing the tomb of Imam Reza the eighth Shia Imam.

\subsection{Instruments}

A battery of five actual TOEFL reading passages plus a Home Culture Attachment Scale (HCAS) was implemented in this study. The reliability of the subscales of HCAS were: Artistic attachment: 0.75 , Cultural attachment: 0.64 , Western attachment: 0.73 , Religious attachment: 0.81 , Nationality attachment: 0.68 .

The HCAS was developed by Pishghadm and Kamyabi (2009) and revalidated by Bazri, Pishghadam, and Hashemi (2013). It consists of 36 items with the reliability of 0.85 Cronbach alpha level (Bazri et al. 2013). The scale is a four point Likert scale ranging from 1 "strongly disagree" to 4 "strongly agree". The underlying construct of HCAS are five basic factors that display Religious, Western, Nationality, Cultural, and Artistic attachments. They are the subscales of HCAS.

\subsection{Data Collection}

In this study, the process of data gathering adopted a quantitative research model. Five TOEFL reading passages plus a "Home culture attachment" questionnaire were distributed among the participants, at the same time a roller ball gel ink pen was given to each participant as an incentive to encourage them to respond more attentively. They were given 90 minutes to read the TOEFL passages, answer the reading comprehension questions and complete the questionnaire.

The data was analyzed with the use of SPSS and AMOS soft- wares. By the use of SPSS, the normality of the scores was examined and then the correlation that existed between the underlying factors of the variables "Home Culture Attachment" and "Reading tests" were assessed. Then AMOS was implemented to run Structural Equation Modeling (SEM) in order to examine the predictability of reading comprehension based on the Home Culture Attachment scale.

\section{Results}

First, descriptive statistics and normality of the questionnaire and reading scores were examined. Descriptive statistics, including the minimum score, maximum score, mean, and standard deviation and also skewness and kurtosis values are shown in Table1. To check the normality of distribution, skewness and kurtosis values were checked. If skewness and kurtosis values were within the range of -2 and +2 , then we were assured that our data have enjoyed normal distribution. As Table 1 shows, all skewness and kurtosis values are within the range of -2 and +2 . It shows that the data enjoy normality. 
Table 1: Descriptive Statistics of reading score and Home Culture Attachment scale and subscales

\begin{tabular}{|l|c|c|c|c|c|c|c|c|c|}
\hline & $\mathrm{N}$ & Minimum & Maximum & Mean & Std. Deviation & \multicolumn{2}{|c|}{ Skewness } & \multicolumn{2}{|c|}{ Kurtosis } \\
\cline { 2 - 10 } & Statistic & Statistic & Statistic & Statistic & Statistic & Statistic & Std. Error & Statistic & Std. Error \\
\hline Reading.score & 228 & 27.00 & 48.00 & 35.5067 & 5.17033 & .484 & .161 & -.555 & .321 \\
Artistic.A & 228 & 5.00 & 20.00 & 14.2683 & 2.83259 & -.141 & .161 & -.168 & .321 \\
Cultural.A & 228 & 10.00 & 28.00 & 19.4625 & 3.51229 & -.063 & .161 & -.323 & .321 \\
Nationality.A & 228 & 11.00 & 24.00 & 20.3046 & 2.46599 & -.651 & .161 & .399 & .321 \\
Religious.A & 228 & 7.00 & 39.00 & 19.3080 & 5.69830 & -.144 & .161 & -.054 & .321 \\
Western.A & 228 & 10.00 & 35.00 & 22.5214 & 4.33246 & -.056 & .161 & .473 & .321 \\
HomeCultureAtt & 228 & 65.00 & 119.00 & 95.8648 & 8.00686 & -.103 & .161 & .579 & .321 \\
Valid N (listwise) & 228 & & & & & & & & \\
\hline
\end{tabular}

Then, the relation between total Home Culture Attachment and the reading score was assessed. As Table 2 shows, there is a significant negative relationship between home culture attachment and reading achievement $(r=-.17, p<.05)$. This negative relation implies that the higher the attachment to the home culture, the lower the learners' reading achievement.

Table 2: Correlation between Home Culture Attachment and Reading Scores

\begin{tabular}{|c|c|}
\hline & Reading score \\
\hline Home culture attachment & $-.174^{\star \star}$ \\
\hline
\end{tabular}

In order to gain more insight into this relationship, the subscales of home culture attachment were examined separately. Results can be seen in Table 3.

Table 3: Correlation between the subscales of Home Culture Attachment and Reading Scores

\begin{tabular}{|c|c|c|c|c|c|}
\hline & Artistic & Cultural & Nationality & Religious & Western \\
\hline Reading score & -.01 & -.05 & $-.15^{\star}$ & $-.13^{\star}$ & -.02 \\
\hline
\end{tabular}

As Table 3 indicates, reading score was negatively and significantly correlated with only Nationality $(r=-.15, p<.05)$ and religious attachment $(r=-.13, p<.05)$. Therefore, the higher the Nationality and religious attachment, the lower is the reading score of the learners. No other significant correlations were found. Moreover, as Table 3 indicates, reading score has the highest negative relation with Iranian attachment. However, it should be mentioned that the correlation of home culture attachment with reading score was not very high.

In order to check the predictability of the reading score based on the subscales of home culture attachment, Structural Equation Modeling (SEM) was used. In this study, a special kind of SEM called path analysis was utilized. Moreover, to check whether the data fits the model, goodness-of-fit indices were used. In this study, $\mathrm{X}^{2} / \mathrm{df}, \mathrm{GFI}, \mathrm{CFI}$, and RMSEA were applied. The final model of reading score based on home culture attachment is shown in Figure 1.

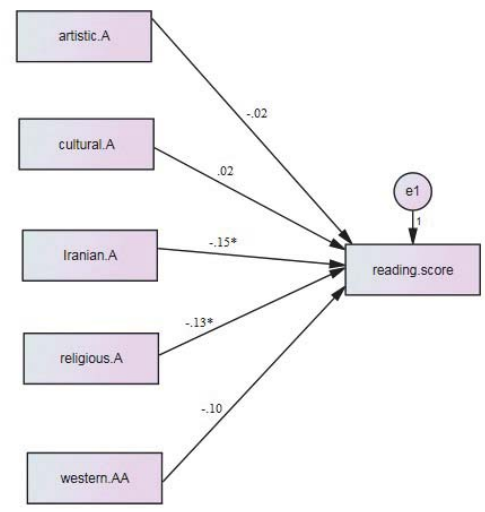

Figure 1. Reading model based on home culture attachment 
Results of path analysis indicated that the model fits the data adequately $\left(X^{2} / \mathrm{df}=1.25, \mathrm{GFI}=.98, \mathrm{CFI}=.99, \mathrm{RMSEA}=.04\right)$. As Figure1 indicates, only two of the subscales of home culture attachment are significant predictors of reading score. Religious attachment $(\beta=-.13, p<.05)$ and Nationality attachment $(\beta=-.15, p<.05)$ are negative significant predictors of reading score. Therefore, these two variables negatively affect reading score the other variables had no significant effect on reading score.

\section{Discussion}

The purpose of the present study was to inspect if there is a relationship between the Home culture attachment of EFL students and their reading comprehension ability in general, and in particular, to investigate the relationships that exists between the underlying factors of home culture attachment which are artistic, cultural, Nationality, religious, and western attachments with the EFL learners' reading comprehension.

This study reaffirms the fact that culture can both enhance and hinder second or foreign language learning. If the learner's home culture is congruent with the target culture, the process of language learning speeds up, but when there is a distance between different aspects of Home and target cultures, and perhaps because of some bias, there will be little flexibility in accepting the target culture by the learners, this will consequently hinder or retard the process of second language learning. The results of this research revealed that there is a significant negative relationship between home culture attachment and reading achievement and this denotes that the higher the attachment to one's home culture, the lower the leaners' reading achievement. More specifically, it is shown that reading score was negatively and significantly correlated with only Nationality and Religious attachments in the sense that the higher the Nationality and Religious attachment, the lower the reading performance will be.

As stated by many language practitioners, the cultural background of a reader affects his or her ability in understanding texts (Anderson, Sapiro \& Montague, 1977; Barnet, 1989; Carrell, 1987; Steffensen, Joag-Dev,\& Anderson,1979) and since the learners are embedded in the cultural context of their own home society, this immersion helps them interpret the concepts in the target language (Kourova \& Modianos, 2013). Self-culture awareness can be considered as a basis for comparing and contrasting the two cultures. This can help learning the foreign language and leads to the development of their competence with target culture (Kun, 2013; Kramsch, 1993).

After the learners have developed their competence with the target culture and language, they make the judgment either to accept or not accept the target cultural concepts. As it is expressed by Berry, Kin, Minde and Mon,(1987) and de Domanico, Crawford and DeWolfe, (1994), the incompatibility between ethnic and mainstream cultures may cause psychological stress or just as Zhang, Morris, Cheng and Yap (2013) have attested it may even disrupt the second language learning processing. Some people are bound to their home culture and adopt ethnocentric views, they ignore or reject the target culture and this causes serious problems in encountering a different culture. The reason is that being bound to one's own culture limits the self and this restriction prevents them from seeing the world through different ways of looking (Genc and Bada, 2005). The results of this study displayed that the EFL learners' binds to Nationality and Religious factors of Home Culture Attachment are stronger than their binds to Artistic, Cultural and Western factors and the reason may be that most of them are living in a religious city and are inevitably affected by the religious practices that are performed in their city and may have a strong feeling in this regard. In Mashhad remarkable importance are also given to great Iranian works of literature and also to distinguished poets and writers. This can also make a strong feeling of pride for the people who live in this city which may affect their judgments in confronting other cultures while learning another language.

The religious factors in HCAS consist of performing religious practices of different kinds, going to religious places and giving enough priority to them. The Nationality factors include: being proud of Iranian heroes, historical monuments, civilization, ceremonies, literature and traditional gatherings. This implies that the more the EFL learners have a bias toward their Religious and National identity the more they limit their views and consequently restrict their comprehension, because they have not rid themselves of ethnocentrism in these two fields and have not developed an open and tolerant value system. It is to be noted that the Artistic factor consists of the learners' preferences in reading Iranian or non-Iranian books and watching Iranian or non-Iranian films. Cultural factors include: How they see the Iranian traditional clothing, restaurants, documentary films, music, architecture, authors and dialects. Western factors are: preferring Western clothes, music, hair style, language, food, culture, ceremonies, shopping from shops with foreign names, using western names for the kids and getting married to a westerner.

This study has revealed that among the subscales of Home Culture Attachment, Religious attachment and Nationality attachment are negative significant predictors of reading score. Therefore, these two variables negatively affect reading score and the other variables had no significant effect on reading score. 
The findings of this study can be implemented in the field of second or foreign language teaching and learning. It reveals that strong religious and national binds to one's own culture entails lower scores in the reading skill. By being aware of this point one can increase his or her flexibility and tolerance in order to comprehend the L2 texts which are part of L2 learning. L2 teachers can also shed light on the point that one can respect and admire his/her religion and nationality and at the same time be flexible enough to tolerate and understand other cultures and other nationalities. This does not mean that we should change identity but it means getting rid of ethnocentric beliefs and developing an open and tolerant value system (Kun, 2013). Since culture is a psycho-social process (Trist, 1990), awareness of cultural values and societal features does not necessarily invite learners to accord with such values as Bada (2000) reminds, they are there to refine the self so that the self can take more universal and less egoistic form (p.100).

This study was performed in a monolingual and mono-religious society. The participants were Iranian Muslims whose mother tongue was Farsi. It would be interesting to perform the same study on a multicultural and multi religious contexts. In that case, a comparison and contrast will be displayed among different nationalities, cultures and religions. In this study, the relevance of Home Culture Attachment to a receptive skill - reading- was assessed. For further investigation its relationship with productive skills (i.e., writing and speaking) can also be examined.

\section{References}

Adaskou, K., Britten, D. y Fashi, B. (1990). Design decisions on the cultural content of a Secondary English course for Morocco, ELT Journal, 44(1), 3-10.

Anderson, R., Sapiro, R., \& Montague,W. (Eds.) (1977). Schooling and the acquisition of knowledge. Hillsdale, NJ: Lawrence Erlbaum Assocs.

Anderson, N.J. (1999). Exploring second language reading. Boston, MA: Heinle \& Heinle.

Bada, E. (2005). Culture in ELT. Cukurova University Journal of Social Sciences (6), 100-110.

Barnett, M. (1989). "Teaching Reading Strategies: How Methodology Affects Course Articulation." Foreign Language Annals, 21, 109-21.

Bazri, E. Pishghadam, R. Hashemi, M.R. (2013). Determining the underlying constructs of the home culture attachment scale and examining the role of English language learning in identity changes of Iranian EFL learners: A Quantitative/ Qualitative study (Master's thesis)

Bernhardt, E. (1991). Reading development in a second language. New York: Ablex.

Berry, J.W. Kin, U., Minde, T. \& Mon, D.(1987). Comparative studies od acculturative stress. International Migration Review, 21,491-511. Buttjes, D. (1990). Teaching foreign language and culture: Social impact and political significance, Laguage Learning Journal, 2,53-57.

Byram, M. \& Morgan C. (1994). Teaching-and-learning language and culture. Clevedon: Multilingual Matters.

Carrell, P.L. (1983). Three components of background knowledge in reading comprehension. Language Learning,33,183-207.

Carrell, P.L. (1987). Content and formal schemata in ESL reading. TESOL Quaterly, 21(3), 461- 481.

Clouet, R. (2006). Between one's own culture and the target culture: the language teacher as intercultural mediator. Porta Linguarum,5,53-62.

de Domanico, Y.B., Crawford, I., \& DeWolfe,A.S.(1994). Ethnic identity and self-concept in Mexican-American adolescents: Is bicultural identity related to stress or better adjustment? Child and Youth Care Forum, 23(3), 197-207.

Genc, B. \& Bada, E. (2005). Culture in language learning and teaching. The Reading Matrix, 5 (1), 73-84.

Hinkel, E. (Ed.) (1999). Culture in second language teaching and learning. Cambridge: Cambridge University Press.

Hinkel, E. (2012). Language learning and language culture in a changing world. Applied Research in English, 1 (2),45-50.

Keith, K. D. (Ed.). (2011). Cross-cultural psychology: contemporary themes and perspectives. United Kingdom: Wiley-Blackwell.

Ketchum, E.M. (2006). The cultural baggage of second language reading: An approach to understanding. Foreign Language Annals, 39,22-42.

Kourova, A. \& Modianos, D.(2013). Inter-cultural awareness and its role in enriching students' communicative competence. The International HETL Review, Special issue 2013, 60-70.

Kramsch, C. (1993). Context and Culture in Language Teaching. Oxford: Oxford University Press.

Kramsch, C. (1998). Language and culture. Oxford: Oxford University Press.

Kun, L. (2013). The culture study in foreign language education. International Review of Social Sciences and Humanities. 6 (1), 196-204.

Lado, R.(1957). Linguistic across cultures: Applied linguistics for language teachers. Ann Ardor: University of Michigan Press.

Lin, L.(2009). Second language learners' identity toward their home culture: Adding pragmatic knowledge to language learning curriculum. Asian Social Science 5 (8),43-51.

Mitchell, R., \& Myles, F. (1998). Second language learning theories. London: Arnold.

Peirce, C. (1868). Questions concerning certain faculties claimed for man in E.C. Moore(ed.). Writings of Charles S. Peirce (Vol. 2: 193211).Bloomington, Indiana: Indiana University Press. 1984.

Pishghadam, R., \& Kamyabi, A. (2009). The relationship between accent and deculturation among EFL learners in Iran. Paper presented at $7^{\text {th }}$ international TELLSI conference, Yazd, Iran

Robinson, G. (1988). Cross-cultural understanding. New York: Prentice-Hall.

Sellami, A. (2000). Teaching towards cultural awareness and intercultural competence: How/Why Culture means? Proceedings of 
teachers of English to speakers of other languages. Vancouver, Canada.

Shahsavandi, Sh., Ghonsooly, B., \& Kamyabi, A. (2010). Designing and validating home culture attachment questionnaire for students of foreign languages and its application. Ferdowsi Review, 1(1), 49-76.

Shotton, R. (1991). Cultural studies in foreign language education, Laguage Learning Journal,3,68-70.

Steffensen, M.S., Joag-Dev, C. \& Anderson, R.C. (1979). A cross-cultural perspective on reading comprehension. Reading Research Quarterly, 15(1), 10-29.

Taylor, Ch. (1991), 'The Dialogical Self' (304-314), in The Interpretive Turn: Philosophy, Science, Culture.( Edited by- David R. Hiley, James F. Bohman, and Richard Shusterman). Cornell University Press.

Trist, E. (1990). Culture as a psycho-social process. In E. Trist, \& H. Murray (Eds.), The social Engagement of social sciences: A Tavistock anthology, 1,539-545. Philadelphia: University of Pennsylvania Press.

Tseng, Y. (1994). Teaching as social semiotics (Unpublished dissertation). Bloomington, Indiana: Indiana University Press.

Tseng, Y. (2002). A Lesson in Culture. ELT Journal 56 (1).11-21.

Yule, G. (1996). Pragmatics. Oxford, England: Oxford University Press.

Widdowson, H.G. (1983). Learning purpose and Language use. Oxford: Oxford University Press.

Zhang, Sh., Morris, M.W.Cheng, Ch. \& Yap, A.J. (2013). Heritage-culture images disrupt immigrants' second-language processing through triggering first-language interference. PNAS 110 (28).11272-11277. 